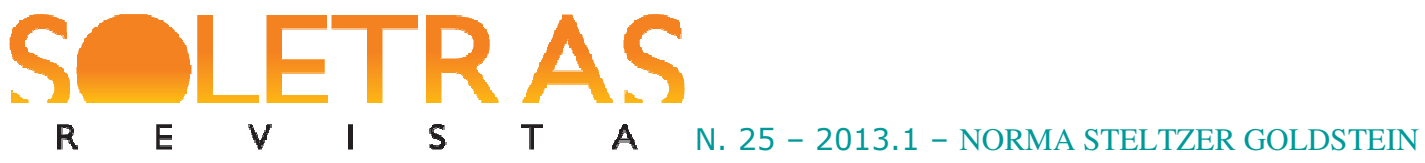

\title{
Traços penumbristas na poesia modernista de Manuel Bandeira ${ }^{1}$
}

\author{
Norma Seltzer Goldstein ${ }^{2}$
}

\begin{abstract}
Resumo: $O$ artigo trata dos aspectos penumbristas da poesia de Manuel Bandeira, predominantes nos três primeiros livros, com o objetivo de avaliar em que medida esses traços permaneceram nas produções posteriores. A análise se apoia em resultados de pesquisas anteriores, voltadas ao levantamento temático e formal dos traços marcantes da poesia bandeiriana. O primeiro levantamento foi aplicado às três primeiras obras (GOLDSTEIN, 1983) e o segundo, à produção posterior (GOLDSTEIN, 1987). Sem ser uma escola literária, o penumbrismo ou crepuscularismo remete à produção de alguns poetas pré-modernistas, dentre eles Manuel Bandeira. A inspiração veio de poetas franceses e italianos, a quem eram caros temas intimistas, ambiências a meia-luz, tom melancólico, recursos sonoros como repetições e sons nasais. No conjunto, o penumbrismo poderia ser considerado como uma estética da atenuação: atenuação de sentimentos, ternura pelo tema, volúpia ambígua, quotidiano, solidariedade. A partir de exemplos, são apresentadas essas características nos três livros iniciais do poeta. Em seguida, em Libertinagem, marcadamente modernista, em que se abre espaço para que algumas marcas penumbristas se façam discretamente presentes. E, seguida, são comentadas as demais obras, nas quais em grau menor ou maior alguns aspectos penumbristas se manifestam, ocorrendo o mesmo nos poemas traduzidos. Percebe-se que parte dos traços penumbristas persiste ao longo da produção do autor, faz parte de seu estilo e convive harmoniosamente com os traços estilísticos do modernismo.
\end{abstract}

Palavras chave: Poesia penumbrista. Poesia modernista. Manuel Bandeira.

Mallarmé tinha razão: "Não é com idéias que se fazem versos: é com palavras".

Só no chão da poesia piso com alguma segurança.

Manuel Bandeira (1957, p. 98; 154).

\section{O primeiro Bandeira}

A poesia de Manuel Bandeira apresenta muitos traços penumbristas ou crepusculares nos três primeiros livros: A cinza das horas (1917); Carnaval (1919) e O ritmo dissoluto (1924). Trata-se de tendência poética presente em autores europeus que Bandeira declara

\footnotetext{
${ }^{1}$ Este texto retoma parcialmente outros dois anteriormente publicados: GOLDSTEIN, 1983; e GOLDSTEIN, 1987.

${ }^{2}$ Graduada, mestre e doutora em Letras pela Universidade de São Paulo e docente da pós-graduação na mesma universidade. Faz pesquisas em Estilística e Linguística Aplicada. Assessora de Língua Portuguesa em escolas de Ensino Fundamental e Médio. Autora, dentre outros, de: Versos, sons ritmos e O texto sem mistérios, ambos pela Editora Ática; e do gênero "Poema" - CD ROM Avaliação de Textos da Olimpíada de Redação Escrevendo o Futuro, CENPEC, 2012. E-mail: ngolds@usp.br.
} 


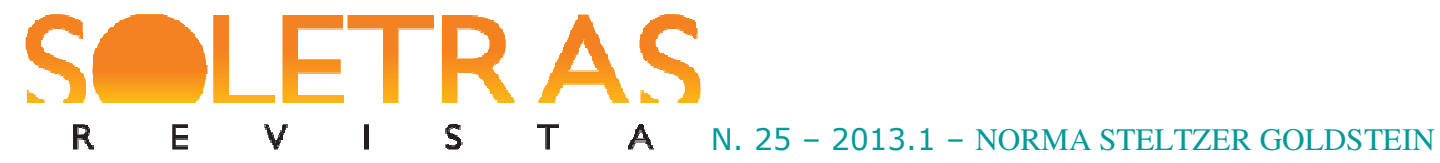

prezar em seu Itinerário de Pasárgada (1957). Os europeus apreciados pelo poeta são franceses - Samain, Guerin, Verhaeren, Francis Jammes - e italianos - Palazzeschi, Soffici, Govoni, Corazzini.

A quarta obra, Libertinagem (1930), é unanimemente apontada como obra madura, marcadamente modernista. A partir do livro seguinte, Estrela da manhã (1936), pinceladas penumbristas ilustram a perenidade do primeiro Bandeira.

No Brasil, os penumbristas não chegaram a formar um grupo propriamente dito. Criavam poemas na mesma linha que inspirava os poetas europeus: temas intimistas; quotidiano; melancolia; volúpia ambígua; gosto pela penumbra e pelos meios-tons; ritmo solto e fluído que prepararia o caminho para o verso livre modernista. Esses traços estão presentes na obra de nossos penumbristas ou crepusculares: Mário Pederneiras, Filipe D'Oliveira, Ronald de Carvalho - criador do termo "penumbrismo", em artigo sobre a poesia de Ribeiro Couto -, Eduardo Guimaraens, Homero Prates, Murilo Araújo, Múcio Leão, Onestaldo de Pennafort, Guilherme de Almeida, Olegário Mariano, Ribeiro Couto, Manuel Bandeira.

$\mathrm{Na}$ maioria dos casos, as características penumbristas estão presentes apenas em parte da obra desses poetas. Ribeiro Couto é exemplo de poeta que permanece nessa linha ao longo de quase toda a produção, já Manuel Bandeira, crepuscular nas primeiras três obras, transformou-se numa das principais figuras de nosso modernismo, conservando alguns traços penumbristas ao longo do tempo.

\section{Penumbrismo: a estética da atenuação}

A estética da atenuação, predominante na poesia penumbrista, manifesta-se de várias formas. Poderíamos falar em atenuação psicológica, traduzida por atitudes e sentimentos como languidez, indecisão, passividade, contemplação, tom confidencial, ternura pelo tema, aceitação, relacionamento amoroso ambíguo: ora mescla de paixão e sentimento fraternal; ora paixão frustrada, seguida de aceitação da não-realização amorosa.

A captação sensorial é atenuada pela meia luz - crepúsculo, penumbra -, pelo meio tom - murmúrio, sons nasais -, por movimentos suaves e lentos.

No plano da sintaxe, as marcas de atenuação se fundem com o nível semântico: associam-se termos de sentido oposto, no mesmo sintagma ou oração. 


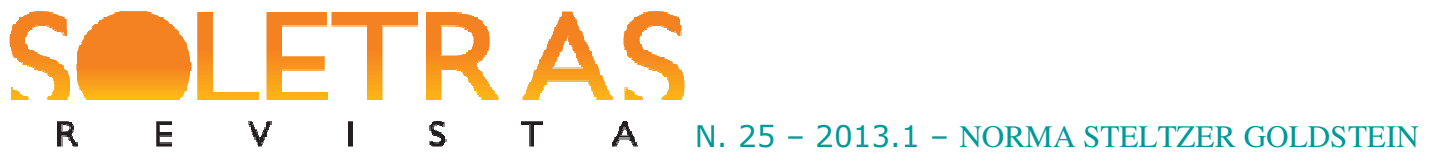

No ritmo, há vários procedimentos de atenuação: ora são empregados versos polimétricos, ora o acento tônico do verso é deslocado para uma posição diversa da usual, ora se percebem duas leituras rítmicas de um mesmo verso, pela flexibilidade de poder situar a sílaba poeticamente acentuada em duas posições diferentes, à escolha do leitor. A estrofação irregular resulta no ritmo solto, numa aproximação do ritmo liberado modernista.

$\mathrm{Na}$ sonoridade, a presença de vogais e consoantes nasais resulta em alongamento fônico que suaviza a musicalidade. Também são frequentes aliterações e assonâncias que sugerem a redução do volume, como se os versos se aproximassem do sussurro.

A temática do quotidiano volta-se, nessa poesia, para aspectos simples e banais da vida. A memória e a recordação estão presentes, não como lembrança de grandes acontecimentos, mas de um momento breve ou de um evento corriqueiro, evocado por um fato simples do presente.

Vistas à distância, essas características não devem surpreender o leitor do século XXI. No entanto, em 1921, o primeiro livro de poemas de Ribeiro Couto foi ao mesmo tempo um sucesso e um escândalo. Na Apresentação da poesia brasileira (s/d., p. 129), Bandeira afirma: "encarado em seu conjunto, o Modernismo brasileiro caracterizou-se por uma atitude destruidora". Nesse sentido, o papel do penumbrismo seria similar ao de uma lenta erosão que deixou marcas definitivas.

\section{Os três primeiros livros}

A maioria dos poemas de Cinza das horas situa-se no universo da atenuação, como ilustram alguns exemplos. O título "Boda espiritual" reúne dois termos opostos, num sintagma em que o adjetivo desloca (e atenua) o sentido do substantivo. Os dois versos abaixo ilustram o mesmo processo de volúpia ambígua, embalados por sons nasais:

No pensamento $\underline{\mathbf{m}} \mathrm{eu}$, amor, tu vives $\underline{\text { nua }}$

Toda nua, pudica e bela, nos $\underline{\text { meus braços. }}{ }^{3}$

O contraste entre os termos "pensamento meu" e "pudica" e as expressões "nua/ toda nua e bela, nos meus braços" atenua a hipótese de realização do abraço amoroso.

\footnotetext{
${ }^{3}$ Todas as referências aos poemas analisados foram retiradas de Bandeira (1966).
} 


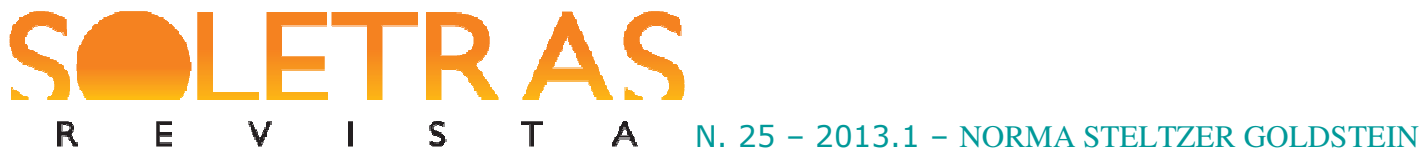

Ocorre o mesmo nos versos que "Pierrot místico", de Carnaval, dirige à amada, melodicamente sustentados pela aliteração:

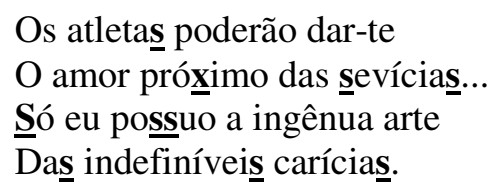

Em Ritmo dissoluto, a temática crepuscular aparece ligeiramente alterada, em relação aos dois livros anteriores, por um tratamento particular que muda o clima do poema, como ilustra "Carinho triste", em que se destacam repetições e paralelismos:

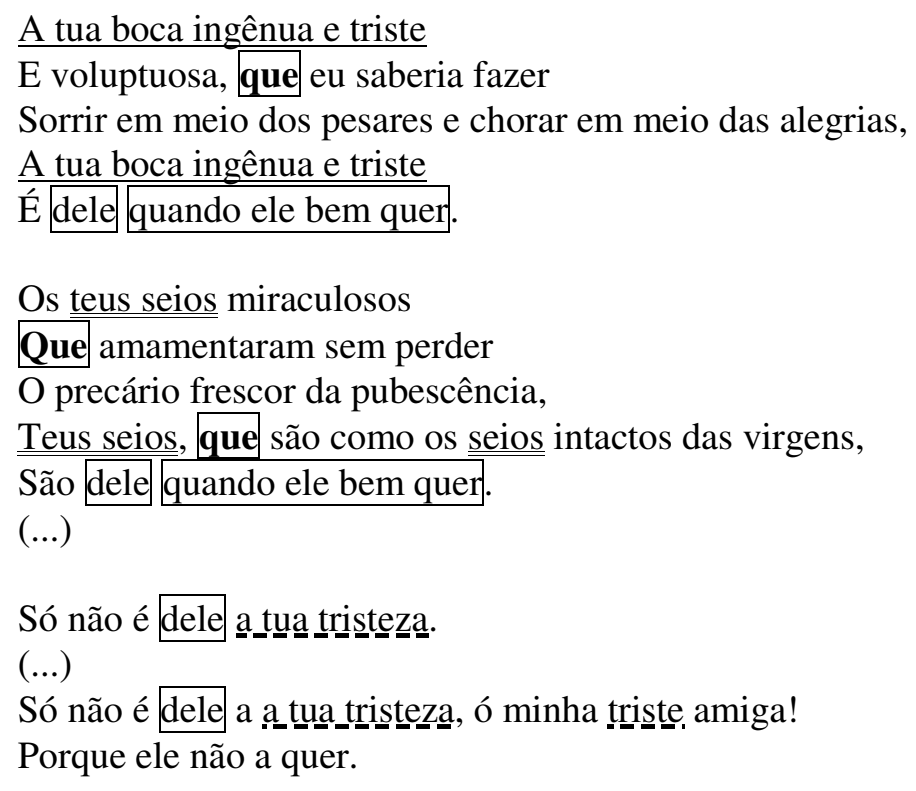

O tom melancólico e a frustração amorosa atenuada remetem ao clima penumbrista, envoltos pelo sentimento de solidariedade em relação à figura feminina do poema - o sentimento de solidariedade está presente em grande parte da obra do poeta. O ritmo solto se cadencia não só em repetições, mas também em rimas irregulares, ora toantes (trIsste / alegrIa

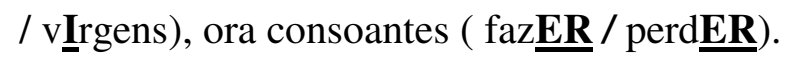

Bandeira trata o quotidiano como elemento de reflexão sobre a condição humana, como em "A estrada", do terceiro livro, moldado em ritmo solto inovador - para a época -, com presença de alguns versos livres. As rimas são quase ausentes, ficando a sonoridade por conta de assonâncias, aliterações, repetições, sons nasais e paralelismos que permeiam o paralelo entre campo e cidade: 


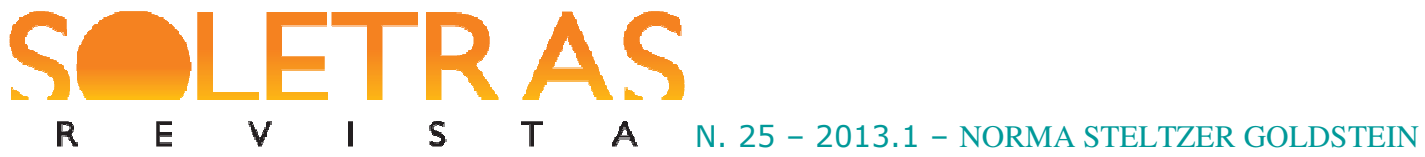

Eșta eștrada onde moro, entre duas voltaș do caminho,

Interesssa mais que uma avenida urbana.

Nas cidades todas as pesssoas se parecem.

Todo o mundo é igual. Todo o mundo é toda gente.

Aqui, não: sente-șe bem que cada um traz șua alma.

Cada criatura é única.

Até os cães.

Eștes cães da roça parecem homens de negócios:

Andam șempre preocupados.

E quanta gente vem e vai!

E tudo tem aquele caráter impresșivo que faz meditar.

Enterro a pé ou a carroc̣inha de leite puxada por um bodezinho

[manhoso

Nem falta um murmúrio d'água, para șugerir pela voz

[dos șímbolos,

Que a vida passa ! que a vida passa !

E que a moçidade vai acabar.

Os indefinidos dos versos três e quatro, ao lado do verbo de ligação, apoiam sintaticamente a significação: a similaridade massificada dos seres citadinos. Nos dois versos seguintes, os seres do campo são particularizados, o que se traduz pela escolha lexical e sintática, novamente: "cada um" opõe-se a "todo o mundo"; em vez do verbo de ligação, é empregado um transitivo direto - "traz" - cujo objeto direto - "alma"- acentua a individualidade das pessoas. A movimentação das pessoas no verso 10 não traduz um valor quantitativo. O importante é que as pessoas sejam percebidas, que sejam identificadas, coisa impossível no cenário urbano. A anáfora da "e", nos versos 10 e 11 sugere a mesma continuidade de "nem" aditivo do verso 13, englobando o quadro campestre e a reflexão final, espécie de chave de ouro deste anti-soneto em quinze versos de ritmo libertado. Às sugestões visuais de cor e movimento do início, somam-se as sugestões auditivas do "murmúrio da água", cuja função simbólica aponta a transitoriedade da vida. Cabe ao leitor escolher como usufruir da mocidade "que vai acabar".

Prevalecem temas intimistas, retratos do quotidiano, gosto pela penumbra e pelos meios-tons, certa melancolia, ritmo solto e fluido - anunciador do verso livre modernista (GOLDSTEIN, 1987).

Esses traços surgem diluídos em $O$ ritmo dissoluto e quase desaparecem em Libertinagem (1930). Neste livro, ganha importância o verso livre - timidamente presente em Carnaval e em metade dos poemas de $O$ ritmo dissoluto.

A partir de Libertinagem, a estética modernista predomina, sem que percam espaço alguns aspectos da primeira fase. 


\section{Traços penumbristas ao longo da obra bandeiriana}

Um tema frequente em Libertinagem é a aceitação, dado permanente no poeta, talvez marca da experiência vivida, ao festejar cada novo amanhecer, numa existência pautada, durante anos, pela espera da morte.

"Não sei dançar" traz a declaração feita na noite de terça-feira gorda: "Uns tomam éter, outros cocaína / Eu tomo alegria!" Este verso - concluído por ponto de exclamação - traduz a aceitação do que a vida trouxe, apesar de todas as perdas.

"Profundamente", composto de duas partes que se espelham, emolduradas pelo passar do tempo, tem a chave de sua interpretação na aceitação, implícita no uso do verbo "dormir", eufemismo para a morte.

Estrela da manhã (1936) apresenta alguns traços penumbristas. Dentre eles, a melancolia e a ternura pelo tema, como em "Marinheiro triste":

Passaste por mim

Tão alheio a tudo

Que nem pressentiste

Marinheiro triste

A onda viril

De fraterno afeto

Em que te envolvi (...).

O título Lira dos cinqüent'anos, de 1940, celebra - em tom discreto e menor, como se esperaria de Bandeira-, o marco da casa dos cinquenta anos. As conquistas modernistas convivem com a retomada de formas tradicionais, dentre elas algumas penumbristas. Exemplo significativo é o "Poema desentranhado de uma prosa de Augusto Frederico Schmidt", - poeta com quem Bandeira tinha afinidade. O tom é de conversa. Bandeira dá voz ao amigo, numa "fala" que retoma versos bandeirianos, mesclando melancolia, aceitação, e recursos sonoros reiterativos, como rimas internas, aliterações, retomadas de termos, sons nasais:

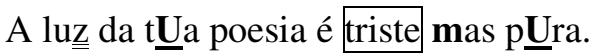

A solidão é o grande sinal do teu dest $\underline{\text { sno. }}$.

O pitoresco, as cores vivas $\underline{\underline{\underline{s}}}$, o mistério e calor dos outros [seres te interessam realmente

Mas tu estás apartado de tudo issso, porque vives $\underline{\underline{\underline{s}}}$ na [companhia dos teus desaparec $\underline{\underline{I}} \mathrm{dos}$,

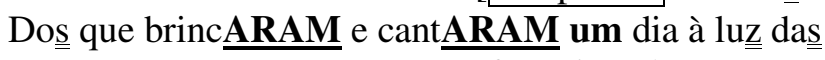
[fogueiras de Sãa João SOLETRAS - Revista do Departamento de Letras da FFP/UERJ Número 25 (jan.-jun. 2013) ISSN: 2316-8838 


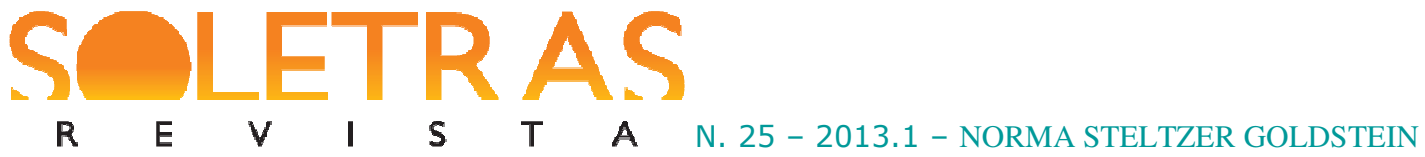

E hoje estão para sempre dormindo profundMENTE.

Da poesia feita como_quem ama e quem morre

Caminhaste para uma poesia de quem vive e recebe trisitEza

NaturalMENTE

- Como o céu esscuro recebe a companhia das primEIras [estrElas.

Na mesma obra, "Versos de Natal" traz um diálogo do poeta com o espelho, "mestre do realismo exato e minucioso", por apresentar a imagem das rugas e dos "olhos tristes e cansados". O poeta agradece e reconhece que esse é seu retrato exterior. A estrofe seguinte começa por um "mas", indicador de oposição, e esboça o retrato interior que o espelho não retrata:

Mas se fosses mágico,

Penetrarias até ao fundo desse homem triste,

Descobririas o menino que sustenta esse homem,

O menino que não quer morrer,

Que não morrerá senão comigo,

O menino que todos os anos na véspera do natal

Pensa ainda em por os chinelinhos atrás da porta.

Percebe-se a ternura pelo tema, assim como o apego ao quotidiano. A partir de um fato banal - olhar-se ao espelho-, o poeta reflete sobre a infância, a vida vivida, o que trazemos dentro de nós como suporte de nossa existência. O termo que remete à infância, "menino", repete-se três vezes, enfatizando a capacidade de sonhar que sustentaria a vida adulta. Nessa passagem também estão presentes a aliteração e o paralelismo.

Em Belo Belo, o poema "O homem e a morte" narra o encontro anunciado no título de forma atenuada e terna, em redondilhas maiores. Destacam-se assonâncias e rimas em - "a" e - "o(ou)" e inversões sintáticas nas frases em que o sujeito da ação é a morte, recurso que ameniza os efeitos inevitáveis da presença da "Indesejada das gentes", ambiguamente Anjo e amada:

$(\ldots)$

- Tu és a Morte? pergunta.

E o Anjo torna: - A Morte sou,

Mestra que jamais engana,

A tua amiga melhor.

E o Anjo foi-se aproximando,

A fronte do homem tocou,

Com infinita doçura

As magras mãos lhe compôs. 


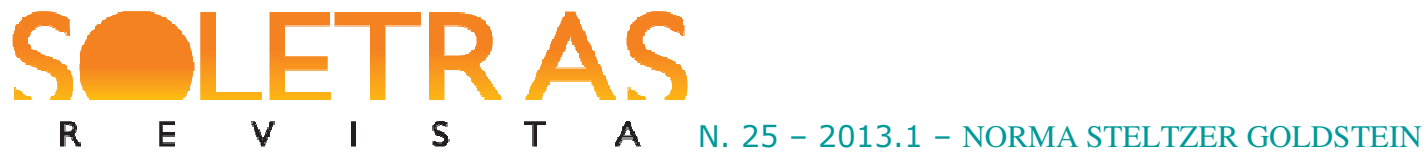

Depois com o maior carinho

Os dois olhos the cerrou...

Era o carinho inefável

De quem ao peito o criou.

Era a doçura da amada

Que amara com mais amor.

Em Opus 10, de 1952, traços penumbristas despontam em alguns textos, como no tom confidencial e na frustração da estrofe final de "Tema e variações", ao lado de repetições e sons nasais:

$$
\begin{aligned}
& \text { Um sonho presente } \\
& \text { Um dia sonhei. } \\
& \text { Chorei, de repente, } \\
& \text { Pois vi, despertado, } \\
& \text { Que tinha sonhado. }
\end{aligned}
$$

Estrela da tarde, editado em 1960 (parcialmente) e em 1963 (de forma completa), também traz composições com aspectos que retomam os três primeiros livros. Trechos do soneto "Mal sem mudança" evidenciam a tristeza e a aceitação, envoltas em sons nasais e aliterações:

(...)

Já não me entendo maiṣ. Meu șubconșciente

Me șerve angústia em vez de fantasia,

Medos em vez de imagens. E em sombria

Pena șe faz pasșado o meu presente.

(...)

Mal șem motivo é o que ora me caștiga,

E ainda que dor menor, mal șem mudança.

\section{Traduções}

A orelha do livro Estrela da vida inteira, de 1966, anuncia que a obra compõe-se de “poesias reunidas acrescidas de Poemas traduzidos”. São 141 textos incluídos pelo próprio autor. Para Samuel Levin (1975, p. 61), em poesia, "forma e conteúdo se fundem". A tradução do poema, portanto, tem de ser particularmente cuidadosa, para dar conta tanto do significante quanto do significado, assim como do contexto de produção que envolveu a criação do original. 


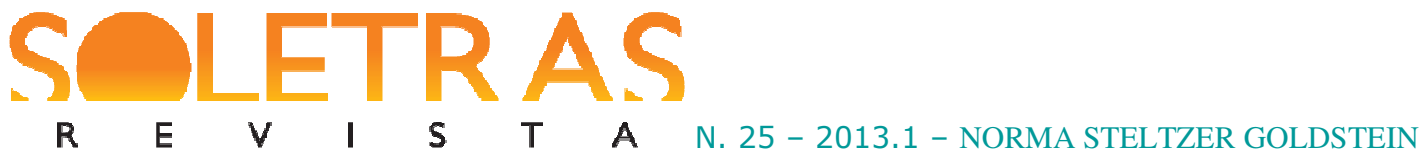

Nos Poemas Traduzidos, a presença de traços como ternura pelo tema, morte, volúpia ambígua, tristeza talvez se explique pelas palavras do próprio tradutor, no seu Itinerário de Pasárgada: "só traduzo bem os poemas que gostaria de ter feito, isto é, os que exprimem coisas que já estavam em mim, mas informuladas" (BANDEIRA, 1957 p. 111). É o caso dos versos de "Renúncia", de Patrícia Morgan:

\author{
Me mantive branca, \\ Me mantive estática; \\ No entanto uma chama \\ De paixão estranha \\ Ardeu dentro de mim. \\ Mas ele não soube, \\ Nem saberá nunca, \\ Tudo que senti... \\ (...)
}

\title{
Trajetória bandeiriana
}

O conjunto da obra de Bandeira revela uma trajetória coerente. As criações marcadamente penumbristas dos primeiros livros já anunciam traços modernistas que se firmarão a partir de Libertinagem. A poesia posterior, predominantemente modernista, reserva espaço para alguns traços penumbristas próprios do poeta e tradutor. Os dois processos se entrecruzam, harmoniosamente, do início ao final.

\section{Referências bibliográficas:}

BANDEIRA, M. Itinerário de Pasárgada. Rio de Janeiro: Livraria São José, 1957.

Apresentação da poesia brasileira. In: Apresentação da poesia brasileira: seguida de Antologia da Poesia Brasileira. São Paulo: Ediouro, s.d., p. 47-159.

Estrela da vida inteira. Rio de Janeiro: José Olympio, 1966.

GEBARA, A. E. L. Libertinagem - espaço e tempo, a ocupação bandeiriana. In: Traços marcantes no percurso poético de Manuel Bandeira. São Paulo: Associação Editorial Humanitas, 2005, p. 23-36.

GEBARA, A.E.L.; TAMBELLI, M. S. F. de S. A intuição na tradução bandeiriana: som sem suor? In: Traços marcantes no percurso poético de Manuel Bandeira. São Paulo: Associação Editorial Humanitas, 2005, p. 155-170.

GOLDSTEIN, N. Do penumbrismo ao modernismo: o primeiro Bandeira e outros poetas significativos. São Paulo: Ática, 1983. 


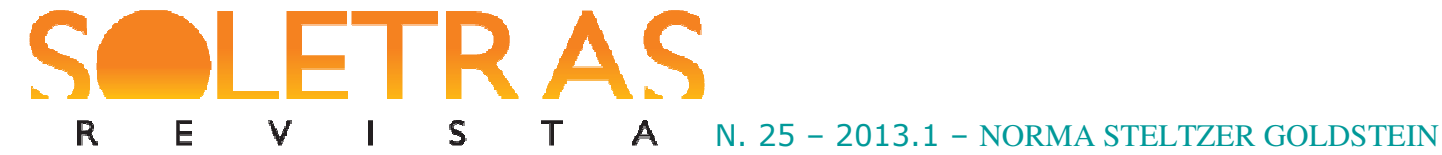

. O primeiro Bandeira e sua permanência. In: LOPEZ, Telê Porto Ancona (Org.) Manuel Bandeira: verso e reverso. São Paulo: Ed. T.A. Queiroz, 1987, p. 8-21.

. Os três primeiros livros de Bandeira. In: Traços marcantes no percurso poético de Manuel Bandeira. São Paulo: Associação Editorial Humanitas, 2005, p. 11-22.

LEVIN, Samuel R. Estruturas Linguísticas em poesia. São Paulo: Cultrix, Editora da Universidade de São Paulo, 1975.

MELO, A. C. A. de. Jogo de Espelhos. Estudo de Opus 10. In Traços marcantes no percurso poético de Manuel Bandeira. São Paulo: Associação Editorial Humanitas, 2005, p. 105-120.

PAULA, J. C. M. de. Estrela da tarde: um círculo que se fecha. In: Traços marcantes no percurso poético de Manuel Bandeira. São Paulo: Associação Editorial Humanitas, 2005, p. 121-136.

PAULA, J. C. M. de; TAMBELLI, M. S. F. de S. Bodas de Bandeira: Lira dos Cinquent'anos "nel mezzo del cammin" In: Traços marcantes no percurso poético de Manuel Bandeira. São Paulo: Associação Editorial Humanitas, 2005, p. 59-82.

SANTORO, E. A. M. Onde está a Estrela da Manhã? In: Traços marcantes no percurso poético de Manuel Bandeira. São Paulo: Associação Editorial Humanitas, 2005, p. 37-58.

SANTOS, E. T. V. dos. Do porão ao sótão: estudo de Belo Belo de Manuel Bandeira. In: Traços marcantes no percurso poético de Manuel Bandeira. São Paulo: Associação Editorial Humanitas, 2005, p. 83-104.

\section{Traits “penumbristas” de la poésie de Manuel Bandeira}

Resumé: Cet article comprend une étude des traits "penumbristas" de la poésie de Manuel Bandeira, qui prédominent dans ses trois premiers livres, ayant le but de vérifier dans quelle mésure ces traits-là restent présents dans la production posterieure de l'auteur. L'analyse est apuyée sur deux recherches précedentes qui ont fait la tables des traits principaux de la poésie de Bandeira. La première a été dediée aux trois premiers livres (GOLDSTEIN, 1983); la seconde, à la production suivante (GOLDSTEIN, 1987). Sans former une école littéraire, le «penumbrismo» ou «crepuscularismo» comprend la production de quelques poètes prémodernistes, parmi eux, Manuel Bandeira. Ils ont été inspirés par quelques poètes français et italiens, qui choisissaient des thèmes intimistes, des ambiances penombrés, le ton melancolique, la sonorité riche em répétitions et phonèmes nasaux. Dans son ensemble, le «penumbrismo» pourrait être consideré comme une esthétique de l'atenuation de sentiments, tendresse pour le thème traité, volupté ambigüe, quotidien, solidarité. Ces caracteristiques-là sont exemplifiées dans les trois premières oeuvres du poète. Ensuite, c'est le tour de Libertinagem, oeuvre nettement moderniste, dans laquelle quelques traits «penumbristas » trouvent encore sa place. Ensuite, sont examinés les oeuvres suivantes, dans lequelles, d'une façon plus évidente ou plus discrète, on trouve des aspects "penumbristas », ainsi que dans 


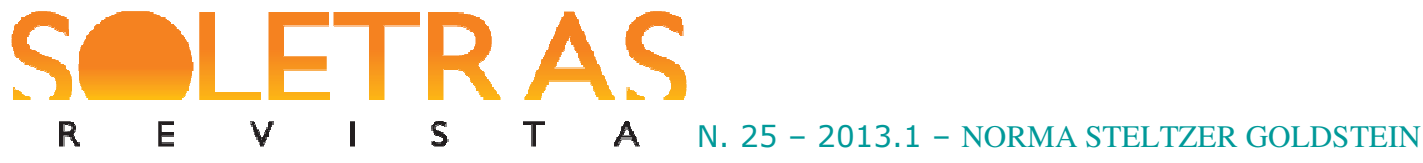

les poèmes traduits. On comprend, donc, que les traits «penumbristas » restent présents tout au long de la production de l'auteur, qu'ils font partie de son style et qu'ils trouvent une harmonie conviviale avec les caractéristiques du modernisme.

Mots-clés: “Penumbrismo”. Poésie Moderniste. Manuel Bandeira.

Recebido em: 20 de maio de 2013.

Aprovado em: 30 de junho de 2013. 